\title{
Effects of TAT-conjugated platinum nanoparticles on lifespan of mitochondrial electron transport complex I-deficient Caenorhabditis elegans, nuo-I
}

This article was published in the following Dove Press journal:

International Journal of Nanomedicine

16 September 2010

Number of times this article has been viewed

\author{
Yuri Sakaue \\ Juewon Kim \\ Yusei Miyamoto \\ Department of Integrated \\ Biosciences, University of Tokyo, \\ Chiba, Japan
}

Correspondence: Yusei Miyamoto Department of Integrated Biosciences, Graduate School of Frontier Sciences, University of Tokyo, Bioscience Building 402, 5-I-5 Kashiwanoha, Kashiwa, Chiba 277-8562, Japan

$\mathrm{Tel}+8 \mid$ 47। 363628

Fax $+8 \mid$ 47। 363630

Email yusei74@k.u-tokyo.ac.jp
Abstract: Platinum nanoparticle (Pt-np) species are superoxide dismutase/catalase mimetics and also have an activity similar to that of mitochondrial electron transport complex I. To examine if this complex I-like activity functions in vivo, we studied the effects of Pt-nps on the lifespan of a mitochondrial complex I-deficient Caenorhabditis elegans mutant, nuo-1 (LB25) compared with wild-type N2. We synthesized a fusion protein of a cell-penetrating peptide, human immunodeficiency virus-1 TAT (48-60), C-terminally linked to a peptide with a high affinity to platinum (GRKKRRQRRRPPQ-DRTSTWR). Pt-nps were functionalized by conjugation with this fusion protein at a 1:1 ratio of TAT-PtBP to Pt atoms. Adult worms were treated with conjugated Pt-nps for 10 days. The mean lifespan of untreated N2 and LB25 was $19.6 \pm 0.4$ and $11.8 \pm 0.3$ days, respectively. Using $5 \mu \mathrm{M}$ of conjugated Pt-nps, the lifespan of N2 and LB25 was maximally extended. This maximal lifespan extension of LB25 was $31.9 \pm 2.6 \%$, which was significantly greater than that of $\mathrm{N} 2(21.1 \pm 1.7 \%, P<0.05$ by Student's $t$-test $)$. Internalization of Pt into the whole body and mitochondria was similar between these two strains. Excessive accumulation of reactive oxygen species was not observed in the cytosol or mitochondria of untreated LB25. Treatment for five days with $5 \mu \mathrm{M}$ conjugated Pt-nps decreased cytosolic and mitochondrial reactive oxygen species in N2 and LB25 to a similar extent. The ratio of $\left[\mathrm{NAD}^{+}\right] /$ $[\mathrm{NADH}]$ was very low in the whole body and mitochondria of control LB25. After five days of treatment with $5 \mu \mathrm{M}$ conjugated Pt-nps, the ratio of $\left[\mathrm{NAD}^{+}\right] /[\mathrm{NADH}]$ was increased in N2 and LB25. However, the degree of the increase was much higher in LB25 than in N2. Pt-nps function as NADH oxidase and recover the $\left[\mathrm{NAD}^{+}\right] /[\mathrm{NADH}]$ ratio in $\mathrm{LB} 25$, leading to effective extension of the lifespan of LB25.

Keywords: platinum nanoparticles, Caenorhabditis elegans, complex I-deficient mutant, LB25, lifespan

\section{Introduction}

Platinum nanoparticles (Pt-nps) are an efficient catalyst for electro-oxidation of hydrogen peroxide $\left(\mathrm{H}_{2} \mathrm{O}_{2}\right) .{ }^{1}$ Owing to this catalase activity, Pt-nps are utilized as a fine element of biosensors. ${ }^{2,3}$ However, Pt-nps have not been developed sufficient for biologic or medical use compared with gold nanoparticles (Au-nps). ${ }^{4-6}$ Recently, some papers have shown biologic and medical application of Pt-nps, including usage as a platform for drug delivery. ${ }^{7-9}$ We regard Pt-nps as a bioactive material, ie, a kind of antioxidant, and have undertaken research on these entities. In vitro Pt-nps scavenge reactive oxygen species (ROS) including superoxide anion $\left(\mathrm{O}_{2}^{-}\right)$as well as $\mathrm{H}_{2} \mathrm{O}_{2}$, and free radicals. ${ }^{1,10}$ Pt-nps seem to have catalytic antioxidant activity. Because the $\mathrm{O}_{2}{ }^{-}$-scavenging activity of Au-nps is less than that of 
Pt-nps, and Au-nps cannot scavenge $\mathrm{H}_{2} \mathrm{O}_{2}$, Pt-nps are a more potent antioxidant than Au-nps. ${ }^{1}$ In vivo we tested the effects of Pt-nps on the lifespan of Caenorhabditis elegans. ${ }^{11}$ Pt-nps extended the lifespan of wild-type N2 and the mitochondrial electron transport complex II mutant, mev-1 (knl), whereas a well known superoxide dismutase/ catalase mimetic, EUK-8, did not do this. Furthermore, Pt-nps exhibited more effective protection of nematodes against acute oxidative stress induced by paraquat than EUK-8. These data suggest that Pt-nps scavenge excessive oxidative stress to elongate the lifespan and survival of nematodes.

Mitochondrial electron transport complex I consists of many subunits and is located in the mitochondrial inner membrane. ${ }^{12}$ This complex is NADH:ubiquinone oxidoreductase that transfers electrons from NADH in the matrix to ubiquinone in the inner membrane, with proton transport from the matrix to the mitochondrial intramembrane space. In some diseases the complex I is deficient or its enzymatic activity is suppressed, leading to generation of an excessive amount of $\mathrm{O}_{2}^{-}$. Accumulated ROS seem to contribute partially to the pathogenesis of those diseases. ${ }^{13-16}$ Recently, we have shown in vitro that Pt-nps have an activity similar to the complex I that drives oxidation of NADH to $\mathrm{NAD}^{+}$, as well as reduction of ubiquinone to ubiqunol. ${ }^{17}$ Although it is still not known if Pt-nps transport protons, we expect that Pt-np species will be an enzymatic mimetic of mitochondrial complex I. Pt-nps are able to mediate oxidation of NADH and reduction of ubiquinone separately. In other words, Pt-nps do not require electrons from $\mathrm{NADH}$ to reduce ubiquinone. We suspect that Pt-nps may accept and release electrons by interaction with water molecules.

A mitochondrial complex I-deficient C. elegans mutant, LB25, is a transgenic strain expressing the nuo- 1 (NADH:ubiquinone oxidoreductase) gene carrying an A $352 \mathrm{~V}$ mutation. ${ }^{18}$ The nuo-1 gene is the $C$. elegans homolog of the human NDUFV1 (NADH dehydrogenase ubiquinone flavoprotein 1) gene encoding the active site subunit of complex I. The A352V mutation corresponds to the residue A341 of the human NDUFV1 gene which causes severe neurologic disorders and muscle atrophy in early childhood. ${ }^{13}$ In this study, we describe the significance of Pt-nps as a mitochondrial complex I mimetic, as well as an antioxidant, in partial recovery of the short lifespan of LB25, indicating that Pt-np species may be a new potent material for diseases with dysfunctional mitochondrial complex I.

\section{Material and methods \\ C. elegans and growth conditions}

Wild-type N2 and a mitochondrial complex I-deficient mutant C. elegans, nuo-1 (LB25), were obtained from the Caenorhabditis Genetic Center (University of Minnesota, St Paul, MN). These strains were maintained at $20^{\circ} \mathrm{C}$ by a popular procedure established by Brenner. ${ }^{19}$ Age-synchronous populations were prepared as previously described. ${ }^{11}$ Briefly, collected eggs were allowed to hatch overnight at $20^{\circ} \mathrm{C}$ in $1 \mathrm{~mL}$ of S-basal buffer $(100 \mathrm{mM} \mathrm{NaCl}, 0.01 \mathrm{mM}$ cholesterol, and $50 \mathrm{mM}$ potassium phosphate, $\mathrm{pH} 6.0$ ), on nematode growth medium agar plates. ${ }^{20}$ Hatched worms (L1 larval stage) were transferred to fresh nematode growth medium agar plates with Escherichia coli OP50 as a food source, and cultured at $20^{\circ} \mathrm{C}$ until the $\mathrm{L} 4$ larval stage.

\section{Preparation of Pt-nps}

Pt-nps were prepared by an ethanol reduction method of hydrogen hexachloroplatinate $\left(\mathrm{H}_{2} \mathrm{PtCl}_{6}\right)$ using poly(N-vinyl-2-pyrrolidone, PVP) as a protecting reagent. ${ }^{11} \mathrm{PVP}, \mathrm{H}_{2} \mathrm{PtCl}_{6} \cdot 6 \mathrm{H}_{2} \mathrm{O}$, and ethanol were purchased from Wako Pure Chemical Industries (Osaka, Japan). Water was freshly prepared with a Millipore Milli-Q Academic Water Purification System (Millipore, Billerica, MA). We estimated the concentration of Pt in Pt-nps from the concentration of $\mathrm{PtCl}_{6}^{2-}$ in a starting reaction mixture, assuming $100 \%$ reduction of $\mathrm{P}^{4+}$ to Pt. Therefore, the Pt-nps concentrations reported herein actually refer to the estimated concentration of Pt atoms present in Pt-nps.

The human immunodeficiency virus (HIV)-1 protein, TAT, is a transcriptional activator of HIV. TAT consists of 86 amino acids, but its translocation activity is associated with the peptide sequence (48-60; GRKKRRQRRRPPQ). ${ }^{21}$ A short peptide (DRTSTWR) is known to be one with high affinity to platinum and is referred to here as a platinumbinding peptide (PtBP). ${ }^{22} \mathrm{~A}$ fusion peptide was synthesized by C-terminally linking of HIV-1 TAT (48-60) to PtBP (GRKKRRQRRRPPQ-DRTSTWR). Pt-nps protected with PVP (PVP-Pt) were conjugated with this fusion protein (TAT-PtBP) at a 1:1 ratio of TAT-PtBP to Pt atom to increase the internalization of Pt-nps into worms. ${ }^{23}$ The consequent conjugate was designated as TAT-PtBP-Pt. Therefore, unconjugated Pt-nps indicates PVP-Pt.

\section{Lifespan assay}

For the lifespan assay, synchronous L4 larvae were transferred to S-medium (S-basal medium supplemented with $3 \mathrm{mM}$ $\mathrm{CaCl}_{2}, 3 \mathrm{mM} \mathrm{MgSO}, 50 \mu \mathrm{M}$ ethylenediamine tetraacetic 
acid [EDTA], $25 \mu \mathrm{M} \mathrm{FeSO}_{4}, 10 \mu \mathrm{M} \mathrm{MnCl}_{2}, 10 \mu \mathrm{M} \mathrm{ZnSO}_{4}$, $1 \mu \mathrm{M} \mathrm{CuSO}_{4}$, and $10 \mathrm{mM} \mathrm{KH}_{2} \mathrm{PO}_{4}$, at $\mathrm{pH} \mathrm{6.0)} \mathrm{with} \mathrm{E.} \mathrm{coli}$ OP50. ${ }^{24}$ We chose a liquid medium because it was difficult to make an agar plate in which TAT-PtBP-Pt were evenly distributed and, furthermore, because worms were allowed to make contact freely with TAT-PtBP-Pt. This transfer day was recorded as Day 0. Nematodes were treated with TATPtBP-Pt for 10 days from Day 0. The worms were transferred to fresh culture medium every second day, and the surviving worms were counted at the same time. Worms that died unnaturally were excluded. The mortality data were subjected to Kaplan-Meier survival analysis to prepare survival curves. Statistical comparisons of mean lifespan values between untreated (control) and treated worms were analyzed by Peto's log-rank test.

\section{Isolation of mitochondria}

Isolation of mitochondria was performed as previously described. ${ }^{18}$ Worms were collected from liquid culture and rinsed three times with $\mathrm{M} 9$ buffer $\left(3 \mathrm{~g} / \mathrm{L} \mathrm{KH}_{2} \mathrm{PO}_{4}, 6 \mathrm{~g} / \mathrm{L}\right.$ $\mathrm{Na}_{2} \mathrm{HPO}_{4}$, and $5 \mathrm{~g} / \mathrm{L} \mathrm{NaCl}$ supplemented with $1 \mathrm{mM} \mathrm{MgSO}_{4}$ and $0.02 \%$ gelatin after autoclaving). Rinsed worms were suspended in $0.2 \mathrm{M}$ mannitol, $70 \mathrm{mM}$ sucrose, 0.1 M EDTA, and $1 \mathrm{mM}$ phenylmethylsulfonyl fluoride at $\mathrm{pH}$ 7.4. Worms were homogenized 10 times by a BRANSON Sonifier 150 with a $3 \mathrm{~mm}$ diameter probe (Branson Ultrasonic Co., Danbury, CT). Homogenized samples were centrifuged three times at $1000 \times \mathrm{g}$ for 10 minutes to eliminate unbroken cells and cuticles. The supernatant was then centrifuged at 19,200 $\times \mathrm{g}$ for 10 minutes to precipitate mitochondria. The pellet was suspended in $0.2 \mathrm{M}$ mannitol, $70 \mathrm{mM}$ sucrose, and $0.1 \mathrm{M}$ EDTA, pH 7.4 (MSE buffer) and centrifuged again. The resultant sediment containing mitochondria was resuspended in $0.5 \mathrm{~mL}$ MSE buffer. Protein concentration was estimated by the Bradford method with a commercially available kit (Bio-Rad, Hercules, CA).

\section{Measurement of platinum content}

On Day 0 , treatments of N2 and LB25 with $5 \mu \mathrm{M}$ TAT-PtBP-Pt were started and continued for five days. Nematodes treated with unconjugated PVP-Pt served as controls. Treated nematodes were rinsed three times with M9 buffer and transferred to crucibles with $1 \mathrm{~mL}$ of $1 \%$ nitric acid, $60 \%$ perchloric acid, and $35 \%$ chloric acid. ${ }^{23}$ The samples ware heated and volatilized at $200^{\circ} \mathrm{C}$ using an electric hot plate, followed by heating with $1 \mathrm{~mL}$ of $1 \%$ nitric acid three times. Finally, the samples were resuspended in $5 \mathrm{~mL}$ of $1 \%$ nitric acid. Determination of amount of $\mathrm{Pt}$ in the resuspended samples was performed.
Measurements of $\mathrm{Pt}$ internalized in mitochondria were performed using similar procedures. The statistical significance of differences between the control and treated groups was determined by Student's $t$-test.

\section{Measurement of reactive oxygen species}

$\mathrm{N} 2$ and LB25 nematodes were treated with $5 \mu \mathrm{M}$ TATPtBP-Pt for five days from Day 0. On day 5, the treated nematodes were washed three times with M9 buffer. The worms were then incubated for 30 minutes at $20^{\circ} \mathrm{C}$ in $2 \mathrm{~mL}$ of Hank's solution $\left(0.44 \mathrm{mM} \mathrm{KH_{2 }} \mathrm{PO}_{4}, 5.37 \mathrm{mM}\right.$ $\mathrm{KCl}, 0.34 \mathrm{mM} \mathrm{Na}_{2} \mathrm{HPO}_{4}, 136.89 \mathrm{mM} \mathrm{NaCl}$, and $5.55 \mathrm{mM}$ D-glucose) containing $10 \mu \mathrm{M}$ 5-(and 6)-chloromethyl2',7'-dichlorodihydrofluorescein diacetate acetyl ester (CM-H_DCFDA) (Sigma-Aldrich Co., St. Louis, MO) and/ or MitoSOX ${ }^{\mathrm{TM}}$ Red (MitoSox, obtained from Invitrogen, Carlsbad, CA). ${ }^{11} \mathrm{CM}-\mathrm{H}_{2}$ DCF released by esterase and MitoSox were fluorescent dyes to assay cytosolic ROS mainly consisting of $\mathrm{H}_{2} \mathrm{O}_{2}$ and mitochondrial $\mathrm{O}_{2}^{-}$, respectively. Worms were fixed with $4 \%$ formaldehyde and mounted on $2 \%$ agarose pads. To determine the fluorescence of CM$\mathrm{H}_{2} \mathrm{DCF}$ and MitoSOX, fixed nematode samples were subjected to Leica TCS SP2 laser scanning confocal microscopy $\left(\mathrm{CM}-\mathrm{H}_{2} \mathrm{DCF}\right.$, excitation at $488 \mathrm{~nm}$ and emission at $510 \mathrm{~nm}$; MitoSOX, excitation at $510 \mathrm{~nm}$ and emission at $580 \mathrm{~nm}$ ). The relative fluorescence of the whole body was determined densitometrically using the LCS Lite software. The statistical significance of differences between the control and treated groups was determined by Student's $t$-test.

\section{$\mathrm{NAD}^{+}$and $\mathrm{NADH}$ assays}

Nematodes were treated with $5 \mu$ M TAT-PtBP-Pt for five days from Day 0. On Day 5, treated animals were rinsed three times with M9 buffer. Rinsed worms were suspended in $100 \mathrm{mM} \mathrm{NaCl}, 1 \% \mathrm{NP}-40,1 \mathrm{mM}$ DTT, 10\% glycerol, and $100 \mathrm{mM}$ Tris, at $\mathrm{pH}$ 8. Worms were homogenized 10 times by BRANSON Sonifier 150 with a $3 \mathrm{~mm}$ diameter probe. Protein concentration was estimated by the Bradford method. We used an $\mathrm{NAD}^{+} / \mathrm{NADH}$ assay kit (Gentaur, Kampenhout, Belgium). Homogenized samples were mixed with $100 \mu \mathrm{L}$ of $\mathrm{NAD}^{+}$extraction buffer for $\mathrm{NAD}^{+}$estimation or $\mathrm{NADH}$ extraction buffer for NADH estimation and heated at $60^{\circ} \mathrm{C}$ for five minutes. Twenty microliters of assay buffer and $100 \mu \mathrm{L}$ of $\mathrm{NADH}$ ( or $\mathrm{NAD}^{+}$) extraction buffer were added. Samples were then vortexed and spun at 10,000 $\times$ rpm for five minutes. The resultant supernatant was used for $\mathrm{NAD}^{+}$and $\mathrm{NADH}$ assays. Similar procedures were performed to determine $\mathrm{NAD}^{+}$and $\mathrm{NADH}$ in isolated mitochondria. The statistical 
significance of differences between the control and treated groups was determined by Student's $t$-test.

\section{Results and discussion}

TAT-PtBP-Pt extends lifespan of wild-type

N2 and nuo-I mutant

The survival of control wild-type N2 and mutant LB25 delineates regular reverse-sigmoid curves (Figure 1A). The mutants died earlier than the wild type. Treatment with $5 \mu \mathrm{M}$ TAT-PtBP-Pt for 10 days from Day 0 shifts the survival curves of N2 and LB25 to the right, indicating extension of their lifespan. The mean lifespan was obtained by calculating the data of the survival curves. The mean lifespans of control N2 and LB25 were $19.6 \pm 0.4$ and $11.8 \pm 0.3$ days, respectively, indicating that the mean lifespan of LB25 is approximately $40 \%$ less than that of N2 (see Table). This result is in good accordance with a previous report. ${ }^{18}$ The concentration of TAT-PtBP-Pt was varied from 1-25 $\mu \mathrm{M}$. While the lifespan of N2 was significantly extended by TAT-
PtBP-Pt only at $5 \mu \mathrm{M}(* * * P<0.001)$, the mutant lifespan was extended by more than $5 \mu \mathrm{M}$ and was maximal at $5 \mu \mathrm{M}$ $\left({ }^{* *} P<0.01(10\right.$ and $25 \mu \mathrm{M}),{ }^{* * *} P<0.001(5 \mu \mathrm{M})$, as shown in Figure 1B and Table 1). The maximal lifespan of LB25 was $15.6 \pm 0.4$ days by $31.9 \pm 2.6 \%$ increase of their control lifespan (see Table 1). Treatment of N2 with $5 \mu \mathrm{M}$ TAT-PtBP-Pt extended the mean lifespan to $23.3 \pm 0.4$ days only by $21.1 \pm 1.7 \%$. TAT-PtBP at $25 \mu \mathrm{M}$ alone did not affect either N2 or LB25 lifespan (Figure 1B and Table 1). These data suggest that Pt in TAT-PtBP-Pt is the active source of the nematode lifespan extension, and the lifespan extension by Pt-nps is significantly more effective in LB25 than in N2 $(P<0.05$ by Student's $t$-test $)$.

Recently, we have performed a similar experiment to monitor the lifespan extension of wild-type nematode N2 by conjugation of Pt-nps with TAT-PTBP. ${ }^{23}$ The lifespan of control N2 was $18.0 \pm 0.3$ days. Treatment with TAT-PtBP-Pt significantly elongated the lifespan in the concentration range $1-50 \mu \mathrm{M}(P<0.001)$. The maximal extension of lifespan

A

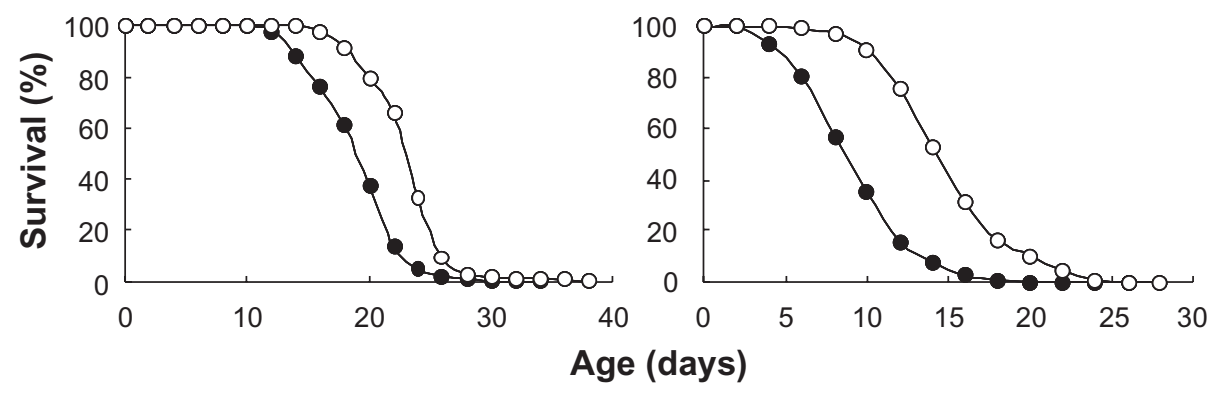

N2

LB25

B

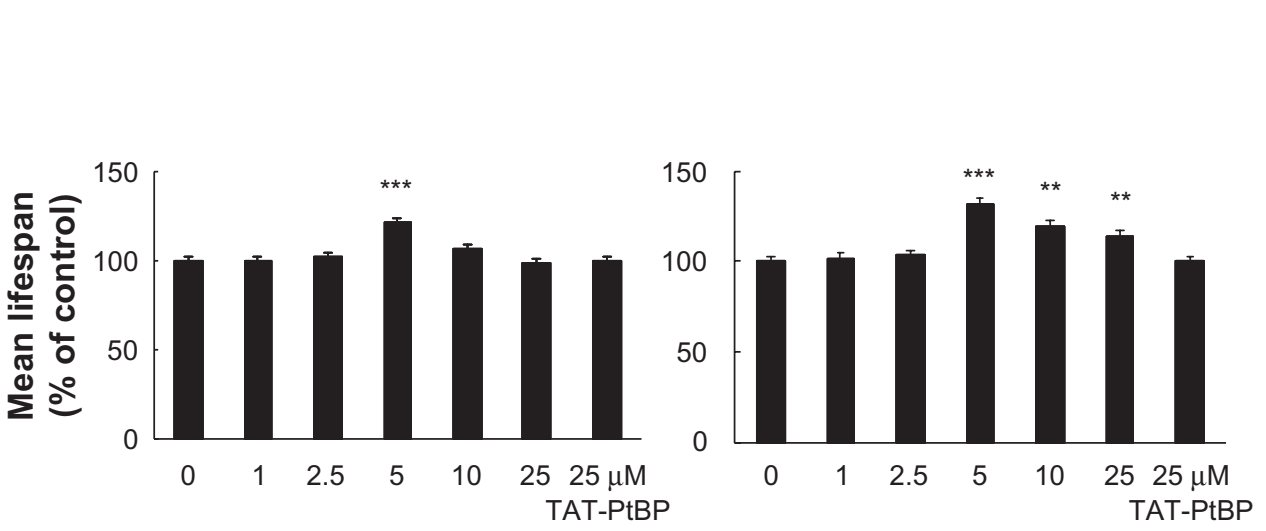

[TAT-PtBP-Pt] $(\mu \mathrm{M})$

Figure I Effects of TAT-PtBP-Pt on the lifespan of N2 and LB25. Adult nematodes were treated with $5 \mu$ M TAT-PtBP-Pt for days 0-10. Shown are survival curves of untreated control $(\bullet)$ and treated $(\circ)$ worms A). The number of worms was $90-95$ in each experiment, and three independent experiments were repeated. The mean lifespan B) was calculated from survival curves. The concentration of Pt in TAT-PtBP-Pt was varied up to $25 \mu \mathrm{M}$. Effect of the fusion protein (TAT-PtBP) at $25 \mu \mathrm{M}$ alone on the lifespan of nematodes was also studied. Error bars represent the standard error of the mean.

Notes: $* * P<0.01$; ***P $<0.001$, as compared with control worms by the log-rank test. The lifespan data are summarized in the Table. 
Table I Effects of TAT-PtBP-Pt on the lifespan of $C$. elegans

\begin{tabular}{llllrll}
\hline Strain & Treatment & $\mu \mathbf{M}$ & $\mathbf{l}$ MS & \multicolumn{1}{l}{$\%$} & $\boldsymbol{P}$ & $\mathbf{n}$ \\
\hline N2 & Control & 0 & $19.6 \pm 0.4$ & & & 91 \\
& TAT-PtBP-Pt & 1 & $19.5 \pm 0.4$ & $-0.2 \pm 2.0$ & 0.628 & 90 \\
& & 2.5 & $19.9 \pm 0.4$ & $1.9 \pm 1.7$ & 0.447 & 90 \\
& & 5 & $23.3 \pm 0.4$ & $21.1 \pm 2.0$ & $3.04 \mathrm{E}-7$ & 90 \\
& & 10 & $20.9 \pm 0.4$ & $6.8 \pm 1.9$ & 0.171 & 90 \\
& & 25 & $19.3 \pm 0.4$ & $-1.5 \pm 2.1$ & 0.462 & 90 \\
LB25 & TAT-PfBP & 25 & $19.3 \pm 0.4$ & $0 \pm 2.1$ & 0.575 & 90 \\
& Control & 0 & $11.8 \pm 0.3$ & & & 93 \\
& TAT-PtBP-Pt & 1 & $12.0 \pm 0.3$ & $2.0 \pm 2.5$ & 0.754 & 90 \\
& & 2.5 & $12.2 \pm 0.3$ & $3.4 \pm 2.5$ & 0.684 & 90 \\
& & 5 & $15.6 \pm 0.4$ & $31.9 \pm 2.6$ & $2.73 \mathrm{E}-4$ & 95 \\
& & 10 & $14.0 \pm 0.3$ & $18.9 \pm 3.6$ & $1.39 \mathrm{E}-3$ & 95 \\
& & 25 & $13.5 \pm 0.4$ & $14.1 \pm 3.0$ & $9.36 \mathrm{E}-3$ & 95 \\
& & 25 & $11.9 \pm 0.3$ & $0.6 \pm 2.5$ & 0.887 & 90 \\
\hline
\end{tabular}

Notes: MLS, mean lifespan (days) presented as mean \pm SEM; \%, change in MLS compared with control, presented as mean \pm SEM.

Abbreviations: SEM, standard error of the mean; MLS, mean lifespan; $n$, number of deaths observed.

was observed with $5 \mu \mathrm{M}$ TAT-PtBP-Pt. The maximal mean lifespan was $22.4 \pm 0.4$ days, resulting in an increase of $24 \%$. The experimental difference between our previous and current studies is the treatment period. Nematodes were treated until death in the previous study, but only for 10 days in the current study.

The optimal increase of life span by TAT-PtBP-Pt was observed at $5 \mu \mathrm{M}$. Greater concentrations of TAT-PtBP-Pt showed less positive effects. Currently, we do not have a clear explanation for this phenomenon. A possible speculation is that the lifespan extension by Pt-nps may gradually decrease with the concentration increase due to toxicity. Pt-nps may extend lifespan by activating cellular signaling via a small change of ROS, but not by a big change. ${ }^{25}$ Further studies are required.

\section{Similar internalization of Pt-nps by $\mathrm{N} 2$ and nuo-I}

The amount of Pt internalized in N2 and LB25 whole bodies by treatment with $5 \mu \mathrm{M}$ unconjugated PVP-Pt for five days from Day 0 was $3.30 \pm 0.05$ and $3.33 \pm 0.12 \mathrm{ng} /$ worm, respectively (Figure 2A). Conjugation of Pt-nps with TAT-PtBP enhances Pt internalization approximately six times in both nematodes $(* * * P<0.001$; amount of internalized Pt in N2 and LB25 whole bodies, $19.9 \pm 0.4$ and $21.3 \pm 0.9 \mathrm{ng} /$ worm, respectively). The mitochondrial Pt accumulation from PVP-Pt was approximately $1 \%$ of the whole body $\mathrm{Pt}$ accumulation $(29.1 \pm 0.8$ and $22.7 \pm 0.3 \mathrm{pg} /$ worm in N2 and LB25 mitochondria, respectively, Figure 2B). Although TAT was used as a cell-penetrating peptide (CPP), it was significantly effective even in mitochondrial translocation $(* * * P<0.001 ; \mathrm{N} 2$ and LB25, $55.3 \pm 2.0$ and $55.7 \pm 0.3 \mathrm{ng} /$ worm, respectively). There was not a significant difference in whole body or mitochondrial accumulation of Pt from TAT-PtBP-Pt between these two strains. Therefore, the more effective lifespan extension of LB25 than N2 by treatment with $5 \mu \mathrm{M}$ TAT-PtBP-Pt is not due to the higher permeability of Pt in LB25 than N2.

CPPs are referred to as protein transduction domains and utilized to facilitate cellular uptake of hydrophilic bioactive large molecules. ${ }^{26}$ TAT is one of the popular CPPs and successful in delivery of proteins, peptides, and nucleotides across the cell membrane. ${ }^{27}$ TAT has been used for protein delivery, even in C. elegans. ${ }^{28}$ CPPs are usually linked to cargoes by covalent binding. ${ }^{29}$ For example, in the case of Au-nps, tiopronin, a kind of spacer, was first covalently bound to gold atoms via a sulfhydryl group during reduction of $\mathrm{AuCl}_{4}^{-}$by $\mathrm{NaBH}_{4} \cdot{ }^{30} \mathrm{TAT}$ was then covalently bound to tiopronin to functionalize the Au-nps. We used PtBP to link TAT to Pt-nps. ${ }^{23}$ This is a unique approach to transcellular delivery of metal-nps. Although precise mechanisms for internalization of Pt-nps into nematodes are unknown, we assume that intestinal permeability of Pt-nps is enhanced by conjugation with TAT-PtBP. Previous studies have shown that TAT conjugation leads Au-nps to nuclear translocation in cells. ${ }^{30,31}$ Furthermore, CPPs interrupt mitochondrial targetting. ${ }^{32}$ Our results indicate that TAT-PtBP conjugation facilitates mitochondrial translocation of Pt-nps to a small but significant extent. We need more sophisticated research on intracellular localization of TAT conjugated Pt-nps.

\section{Reactive oxygen species in cytosol and mitochondria of N2 and nuo-I}

The effects of TAT-PtBP-Pt treatment on ROS were investigated in N2 and LB25. Typical fluorescence from cytosolic $\mathrm{CM}-\mathrm{H}_{2} \mathrm{DCF}$ in the whole body is shown in Figure 3A-D (A, control N2; B, treated N2; C, control LB25; D, treated LB25). The fluorescent intensity obtained using LCS Lite software was similar between control N2 and LB25 (46.4 \pm 2.8 and $42.5 \pm 2.8$, respectively). The relative fluorescence is shown in Figure 3E. Treatment with $5 \mu \mathrm{M}$ TAT-PtBP-Pt for five days from Day 0 significantly decreased the fluorescence, and the extent of this reduction was also similar between these two strains $(-39.2 \pm 2.1$ and $-33.7 \pm 1.8 \%$, respectively, $\left.{ }^{*} P<0.05\right)$. Mitochondrial $\mathrm{O}_{2}^{-}$was also measured with MitoSox in Figure 4A-D; A, control N2; B, treated N2; C, control LB25; D, treated LB25). The fluorescent intensity 
A

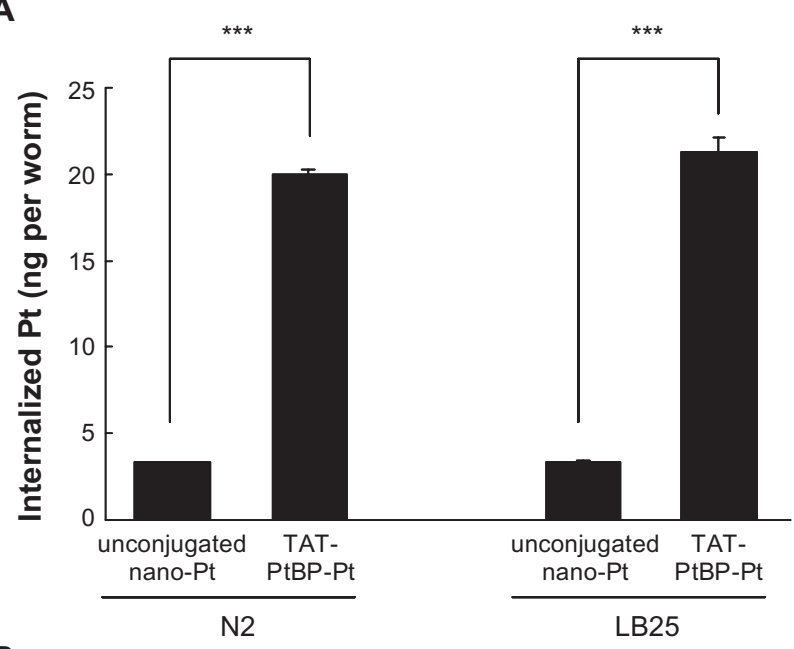

B

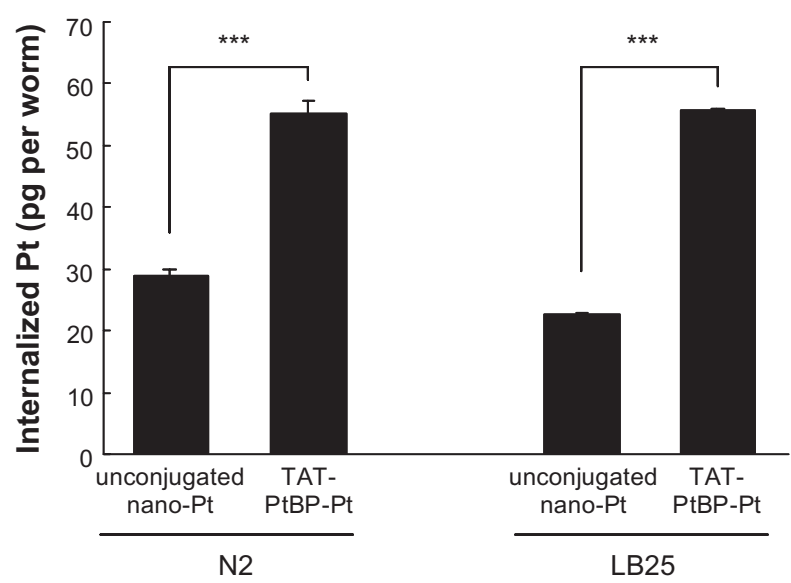

Figure 2 Amount of Pt internalized in whole bodies and mitochondria of N2 and LB25. Animals were treated with $5 \mu$ M TAT-PtBP-Pt for five days from Day 0. Pt accumulation in worm whole bodies $\mathbf{A}$ ) and mitochondria $\mathbf{B}$ ) was determined by an inductively-coupled plasma mass spectrometer ICP-MS. For control, unconjugated Pt-nps (PVP-Pt) was used. The number of worms used was 100 and 500-508 in each measurement for whole bodies and mitochondria, respectively, and three independent experiments were repeated. Error bars represent the standard error of the mean.

Note: Statistical significance was determined by Student's $t$-test $(* * * P<0.001)$.

from mitochondrial MitoSox was $48.0 \pm 3.0$ and $45.7 \pm 2.8$ in control N2 and LB25, respectively (Figure 4E depicted with relative fluorescence). A similar treatment with $5 \mu \mathrm{M}$ TAT-PtBP-Pt significantly decreased the MitoSox fluorescence $(39.6 \pm 2.7 ; * P<0.05$ and $35.9 \pm 2.0 ; * * P<0.01$ as intensity in N2 and LB25, respectively). These results show that ROS accumulation in control LB25 is not excessive, and TAT-PtBP-Pt treatment decreases ROS in N2 and LB25 to a similar extent. A main cause of the short life of LB25 may not be ROS accumulation.

We measured cytosolic and mitochondrial ROS in LB25 for the first time. Excessive accumulation of ROS was not observed in the cytosol or mitochondria of control LB25 in comparison with control N2. We think that the quantification of ROS level is insufficient due to the ROS estimation by
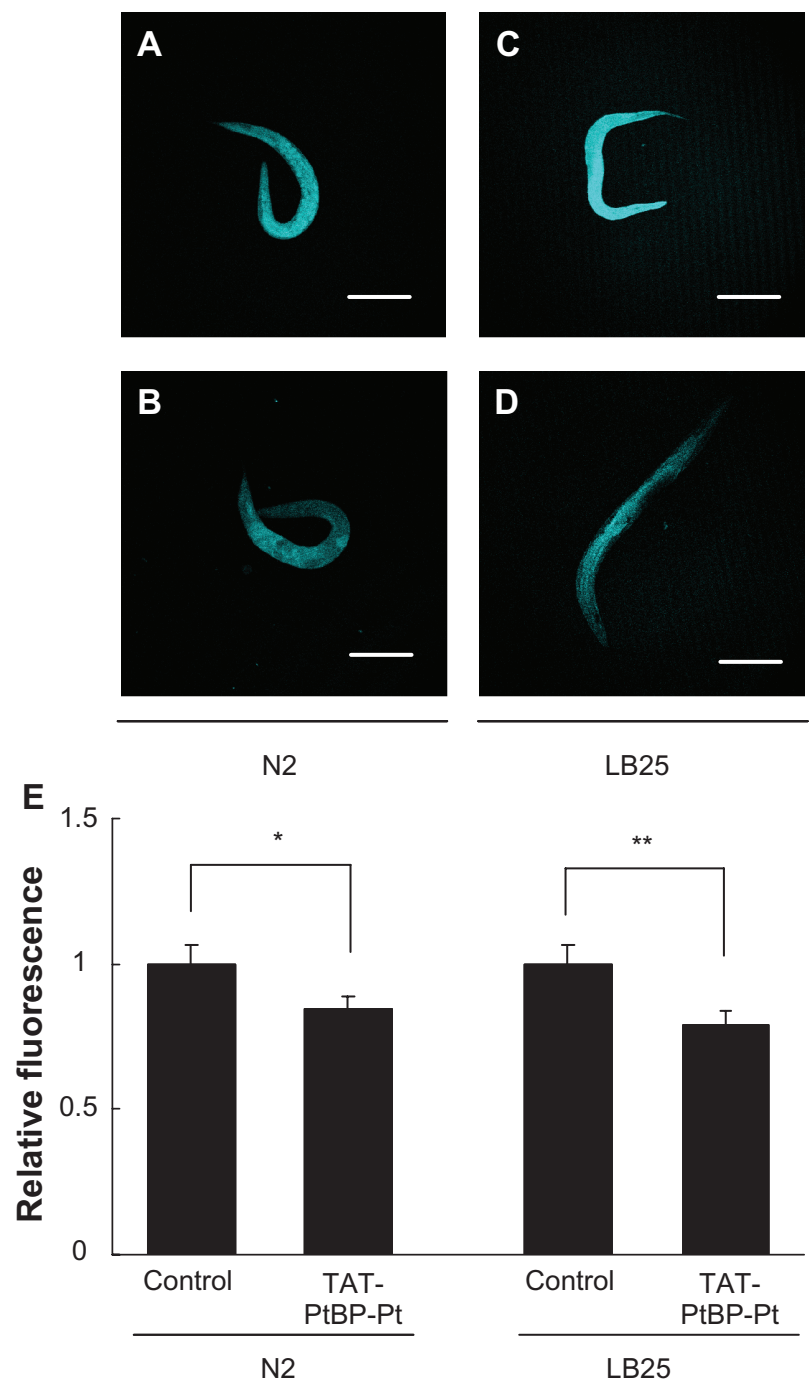

LB25

Figure 3 Effects of TAT-PtBP-Pt on cytosolic reactive oxygen species in N2 and LB25. Animals were treated with $5 \mu$ M TAT-PtBP-Pt for five days from Day 0 . Worms were then treated with $10 \mu \mathrm{M} \mathrm{CM}-\mathrm{H}_{2}$ DCFDA for 30 minutes at $20^{\circ} \mathrm{C}$. Fluorescence was measured by confocal florescence microscopy (Ex $488 \mathrm{~nm}$ and Em $510 \mathrm{~nm}$ ). Shown is cytosolic reactive oxygen species in N2 and LB-25 whole bodies: A) control N2; B) treated N2; C) control LB25; D) treated LB25. The panel E) shows the average of relative intensity for three independent experiments with 10 worms per each experiment. Error bars represent the standard error of the mean.

Notes: $* P<0.05$; $* * P<0.01$, as compared with control worms by Student's t-test.

fluorescent dyes. However, these results are still interesting. It has been reported that 1-methyl-4-phenylpyridinium and rotenone, inhibitors of complex I, lead to NADH-dependent generation of $\mathrm{O}_{2}{ }^{-}$using prepared bovine mitochondrial particles. ${ }^{33}$ However, this increase of $\mathrm{O}_{2}{ }^{-}$generation by the inhibitors was measured for a short period. Thus, we have to study the perturbation of ROS level by suppression of complex I for a long time in vivo. In fact, oxygen consumption was reduced by $50 \%$ in LB25, compared with N2. ${ }^{18}$ Decreased oxygen consumption is supposed to help decrease the generation of ROS. Currently, we do not know how LB25 worms maintain ROS at a relatively normal level during life. Because the 

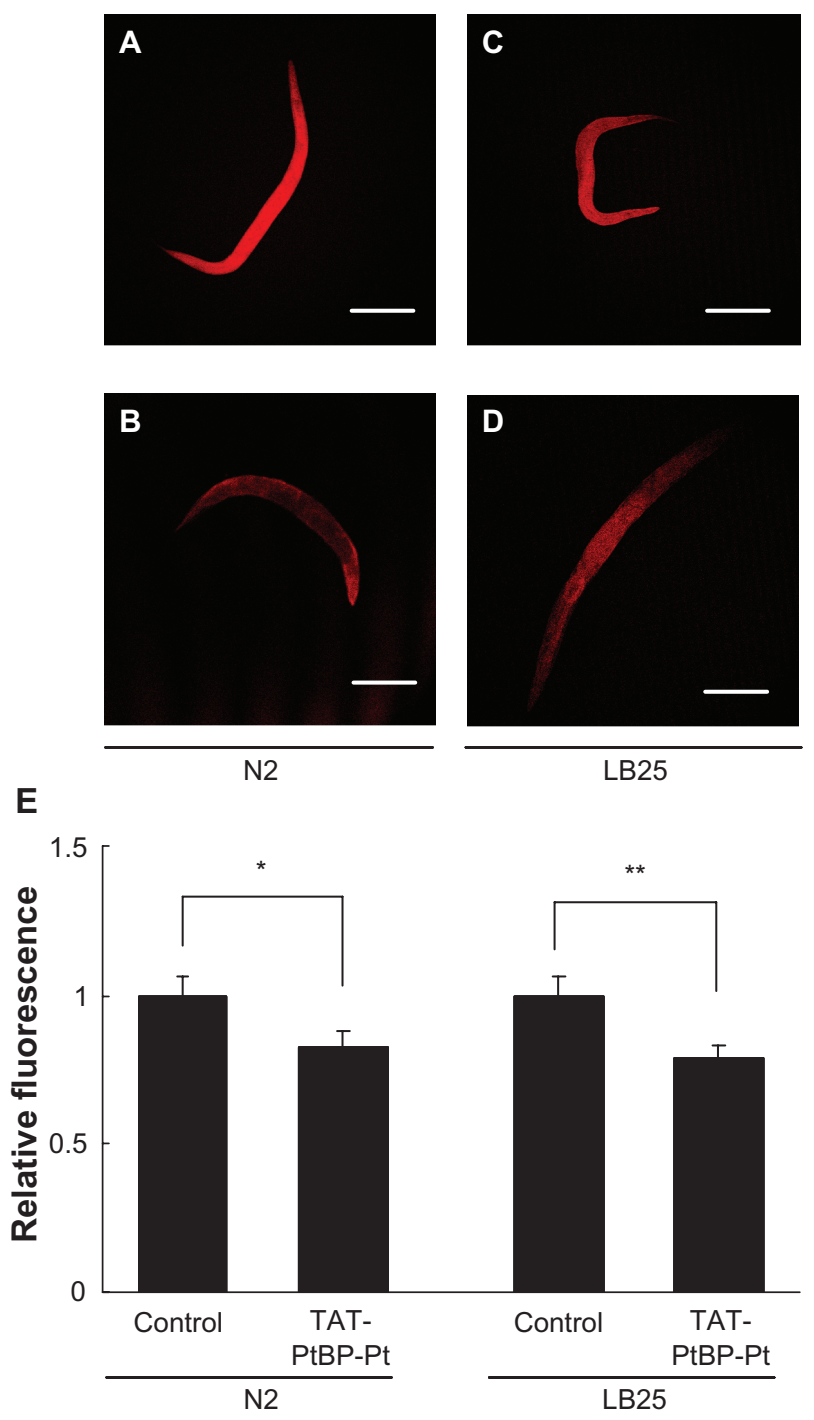

Figure 4 Effects of TAT-PtBP-Pt on $\mathrm{O}_{2}^{-}$in N2 and LB mitochondria. Animals were cultured with TAT-PtBP-Pt for five days from Day 0 . Worms were then treated with $10 \mu \mathrm{M}$ MitoSOX for 30 minutes at $20^{\circ} \mathrm{C}$. Fluorescence was measured by confocal florescence microscopy (Ex $510 \mathrm{~nm}$ and $\mathrm{Em} 580 \mathrm{~nm}$ ). Shown is $\mathrm{O}_{2}^{-}$in N2 and LB25 mitochondria: A) control N2; B) treated N2; C) control LB25; D) treated LB25. The panel E) shows the average of relative intensity for three independent experiments with 10 worms per each experiment. Error bars represent the SEM. Notes: $* p<0.05$; $* * p<0.01$, as compared with control worms by Student's t-test.

oxidative state must be high in LB25, oxidized substances may be accumulated to reduce free ROS. Oxidative marker assays will be required.

\section{Increase of $\left[\mathrm{NAD}^{+}\right] /[\mathrm{NADH}]$ ratio in nuo- $I$ by TAT-PtBP-Pt}

We measured $\mathrm{NAD}^{+}$and $\mathrm{NADH}$ levels in the whole body homogenate and mitochondrial fraction from N2 and LB25. The $\left[\mathrm{NAD}^{+}\right] /[\mathrm{NADH}]$ ratio was considerably smaller in the whole body $(0.057 \pm 0.004)$ and mitochondria $(0.026 \pm 0.005)$ of control LB25 than in those of control N2 (whole body, $0.167 \pm 0.005$; mitochondria, $0.146 \pm 0.006)$, indicating excessive accumulation of NADH in LB25 (Figure 5). Treatment of N2 with $5 \mu \mathrm{M}$ TAT-PtBP-Pt significantly increased the $\left[\mathrm{NAD}^{+}\right] /[\mathrm{NADH}]$ ratio by approximately twice $(* * * P<0.001)$. A similar treatment of LB25 with $5 \mu \mathrm{M}$ TAT-PtBP-Pt greatly increased the $\left[\mathrm{NAD}^{+}\right] /[\mathrm{NADH}]$ ratio by 4.6 and 8.8 times in whole body and mitochondria, respectively $(* * * P<0.001)$. These results indicate that Pt-nps function as NADH oxidase in C. elegans, and accumulated NADH in LB25 is efficiently oxidized to $\mathrm{NAD}^{+}$. This recovery of the $\left[\mathrm{NAD}^{+}\right] /[\mathrm{NADH}]$ ratio may take part in the effective lifespan extension of LB25.

In nuo-1 mutants, including LB25, excessive cellular NADH caused reduction of pyruvate to lactate. ${ }^{18}$ Depletion of pyruvate slows down tricarboxylic acid cycle and oxidative phosphorylation. We believe that Pt-nps oxidize NADH to $\mathrm{NAD}^{+}$to normalize the $\mathrm{NAD}^{+} / \mathrm{NADH}$ ratio, which recovers

A

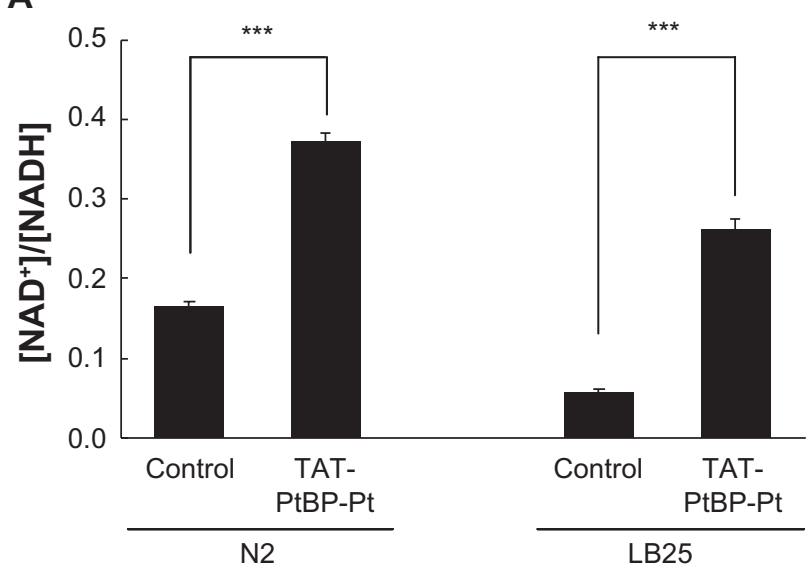

B

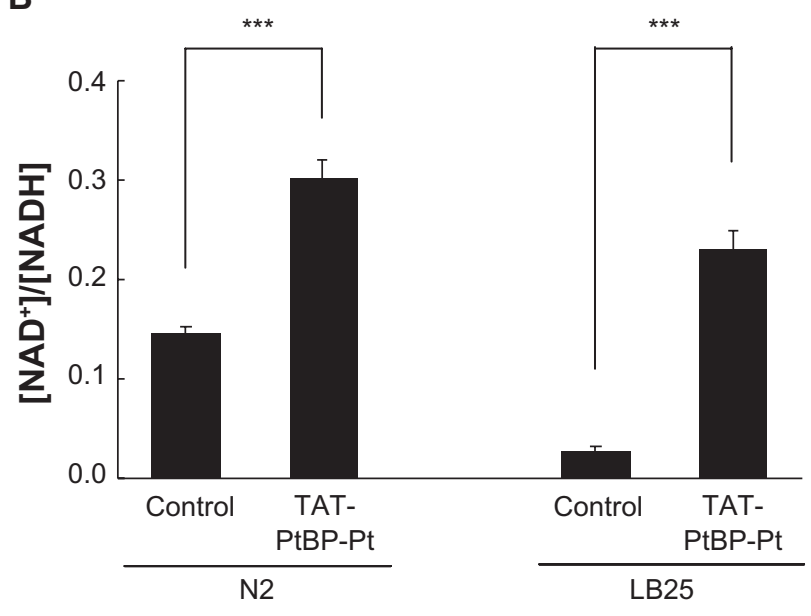

Figure 5 Effects of TAT-PtBP-Pt on the $\left[\mathrm{NAD}^{+}\right] /[\mathrm{NADH}]$ ratio in $\mathrm{N} 2$ and $\mathrm{LB} 25$ The concentrations of $\mathrm{NAD}^{+}$and $\mathrm{NADH}$ were measured in whole bodies $\mathbf{A}$ ) and mitochondria B) using an assay kit. The number of worms was 100 and 500 in each measurement for whole bodies and mitochondria, respectively, and three independent experiments were repeated. Error bars represent the standard error of the mean.

Note: ${ }^{* * *} P<0.001$ as compared with control worms by Student's $t$-test. 
these metabolic pathways and increases adenosine triphosphate synthesis, even though the activity of complex IV is decreased by approximately $50 \%{ }^{18}$ Increase of adenosine triphosphate helps recover the short life of LB25. One may think that accelerated oxidative phosphorylation may produce $\mathrm{O}_{2}^{-}$as a byproduct because LB25 has the low activity of complex I. Pt-nps are able to scavenge ROS including $\mathrm{O}_{2}^{-}$. A similar decrease of ROS by TAT-PtBP-Pt treatment was observed in the cytosol and mitochondria of N2 and LB25 (Figures 3 and 4). However, if Pt-nps efficiently scavenge more ROS in treated LB25, a similar decrease of ROS may be apparent. The lifespan recovery of LB25 by Pt-nps may be supported by the maintenance of ROS using Pt-nps. We believe that the NADH oxidase activity of Pt-nps in scavenging ROS plays a pivotal role in effective recovery of the short lifespan of LB25.

Furthermore, even in wild-type N2, the $\left[\mathrm{NAD}^{+}\right] /[\mathrm{NADH}]$ ratio was increased by treatment with Pt-nps. The $\mathrm{NAD}^{+}-$ dependent SIR-2.1 pathway may be involved in the lifespan extension caused by treatment with Pt-nps. ${ }^{34}$ If it is, this signal pathway seems to be more effective in LB25 to elongate the lifespan because of a marked increase of $\mathrm{NAD}^{+}$by Pt-nps treatment.

\section{Conclusion}

Pt-nps functionalized with a TAT fusion protein are internalized in the mitochondria as well as in the cytosol and exert NADH oxidase activity. Therefore, Pt-np species may be a potent medicinal material to improve symptoms caused by mitochondrial complex I defect. Active targeting of the Pt-nps to mitochondrial matrix and/or inner membrane using signal peptides will be helpful to develop this potency further.

\section{Acknowledgment}

This work was supported in part by a Grant-in-Aid for Scientific Research from the Ministry of Education, Culture, Sports, Science, and Technology, Japan.

\section{Disclosure}

The authors report no conflicts of interest in this work.

\section{References}

1. Kajita M, Hikosaka K, Iitsuka M, Kanayama A, Toshima N, Miyamoto Y. Platinum nanoparticle is a useful scavenger of superoxide anion and hydrogen peroxide. Free Rad Res. 2007;41:615-626.

2. Cao Z, Zou Y, Xiang C, Sun LX, Xu F. Amperometric glucose biosensor based on ultrafine platinum nanoparticles. Anal Lett. 2007;40: 2116-2127.

3. Polsky R, Gill R, Kaganovsky L, Willner I. Nucleic acid-functionalized Pt nanoparticles: Catalytic labels for the amplified electrochemical detection of biomolecules. Anal Chem. 2006;78:2268-2271.
4. Bhattacharya R, Mukherjee P. Biological properties of "naked" metal nanoparticles. Adv Drug Deliv Rev. 2008;60:1289-1306.

5. Boisselier E, Astruc D. Gold nanoparticles in nanomedicine: Preparation, imaging, diagnostics, therapies and toxicity. Chem Soc Rev. 2009; 38:1759-1782.

6. Ghosh P, Han G, De M, Kim CK, Rotello VM. Gold nanoparticles in delivery applications. Adv Drug Deliv Rev. 2008;60:1307-1315.

7. Barone M, Sciortino MT, Zaccaria D, Mazzaglia A, Sortino S. Nitric oxide photocaging platinum nanoparticles with anticancer potential. J Mater Chem. 2008;18:5531-5536.

8. Zang L, Laug L, Münchgesang W, et al. Reducing stress on cells with apoferritin-encapsulated platinum nanoparticles. Nano Lett. 2010;19: 219-223.

9. Pelka J, Gehrke H, Esselen M, et al. Cellular upake of platinum nanoparticles in human colon carcinoma cells and their impact on cellular redox systems and DNA integrity. Chem Res Toxicol. 2009;22:649-659.

10. Watanabe A, Kajita M, Kim J, et al. In vitro free radical scavenging activity of platinum nanoparticles. Nanotechnology. 2009;20:455105.

11. Kim J, Takahashi M, Shimizu T, et al. Effects of a potent antioxidant, platinum nanoparticle, on the lifespan of Caenorhabditis elegans. Mech Ageing Dev. 2008;129:322-331.

12. Hirst J. Towards the molecular mechanism of respiratory complex I. Biochem J. 2010;425:327-339.

13. Schuelke M, Smeitink J, Mariman E, et al. Mutant NDUFV1 subunit of mitochondrial complex I causes leukodyatrophy and myoclonic epilepsy. Nat Genet. 1999;21:260-261.

14. Bénit P, Chretien D, Kadhom N, et al. Large-scale deletion and point mutations of nuclear NDUFV1 and NOUFS1 genes in mitochondrial complex I deficiency. Am J Hum Genet. 2001;68:1344-1352.

15. Winklhofer K, Haass C. Mitochondrial dysfunction in Parkinson's disease. Biochim Biophys Acta. 2010;1802:29-44.

16. Korenaga M, Okuda M, Otani K, Wang T, Li Y, Weinman SA. Mitochondrial dysfunction in hepatitis C. J Clin Gasteroenterol. 2005;39: s162-s166.

17. Hikosaka K, Kim J, Kajita M, Kanayama A, Miyamoto Y. Platinum nanoparticles have an activity similar to mitochondrial NADH: Ubiquinone oxidoreductase. Colloids Surf Biointerfaces. 2008;66:195-200.

18. Grad LI, Lemire BD. Mitochondrial complex I mutations in Caenorhabditis elegans produce cytochrome c oxidase deficiency, oxidative stress and vitamin-responsive lactic acidosis. Hum Mol Genet. 2004;13:303-314.

19. Brenner S. The genetics of Caenorhabditis elegans. Genetics. 1974;77: 71-94.

20. Sulston JE, Brenner S. The DNA of Caenorhabditis elegans. Genetics. 1974;77:95-104.

21. Järver P, Langel Ü. Cell-penetrating peptides $-\mathrm{A}$ brief introduction. Biochim Biophys Acta. 2006;1758:260-263.

22. Sarikaya M, Tamerler C, Jen AKY, Schulten K, Baneyx F. Molecular biomimetics: Nanotechnology through biology. Nat Mater. 2003;2: $577-585$.

23. Kim J, Shirasawa T, Miyamoto Y. The effect of TAT conjugated platinum nanoparticles on lifespan in a nematode Caenorhabditis elegans model. Biomaterials. 2010;31:5849-5854.

24. Johnson TE, Wood WB. Genetic analysis of the life-span of Caenorhabditis elegans. Proc Natl Acad Sci U SA. 1982;79:6603-6607.

25. Heidler T, Harwing K, Daniel H, Wenzel U. Caenorhabditis elegans lifespan extension caused by treatment with an orally activity ROS-generator in dependent on DAF-16 and SIR-2.1. Biogerontology. 2010;11:183-195.

26. El-Andaloussi S, Holm T, Langel Ü. Cell-penetrating peptides: Mechanisms and Applications. Curr Pharm Des. 2005;11:3597-3611.

27. Vivès E, Lebleu, B. The tat-derived cell-penetrating peptide. In: Langel, Ü, editor. Cell-Penetrating Peptides: Processes and Applications. Boca Raton, FL: CRC Press LLC; 2002.

28. Delom F, Fessart D, Caruso ME, Chevet E. Tat-mediated protein delivery in living Caenorhabditis elegans. Biochem Biophys Res Commun. 2007;352:587-591. 
29. Wagstaff KM, Jans DA. Protein transduction: Cell penetrating peptides and their therapeutic applications. Curr Med Chem. 2006;13: 1371-1387.

30. de la Fuente JM, Berry CC. Tat peptide as an efficient molecule to translocate gold nanoparticles into the cell nucleus. Bioconjug Chem. 2005; 16:1176-1180.

31. Berry CC, de la Fuente JM, Mullin M, Chu SWI, Curtis ASG. Nuclear localization of HIV-1 tat functionalized gold nanoparticles. IEEE Trans Nanobiosci. 2007;6:262-269.

32. Ross MF, Murphy MP. Cell-penetrating peptides are excluded from the mitochondrial matrix. Biochem Soc Trans. 2004;32:1072-1074.
33. Hasegawa E, Takeshige K, Oishi T, Murai Y, Minakami S. 1-Methyl4-phenylpyridinium $\left(\mathrm{MPP}^{+}\right)$induces NADH-dependent superoxide formation and enhances NADH-dependent lipid peroxidation in bovine heart submitochondrial particles. Biochem Biophys Res Commun. 1990;170:1049-1055.

34. Tissenbaum H, Gurente L. Increased dosage of a sir-2 gene extends lifespan in Caenorhabditis elegans. Nature. 2001;410:227-230.
International Journal of Nanomedicine

\section{Publish your work in this journal}

The International Journal of Nanomedicine is an international, peerreviewed journal focusing on the application of nanotechnology in diagnostics, therapeutics, and drug delivery systems throughout the biomedical field. This journal is indexed on PubMed Central,

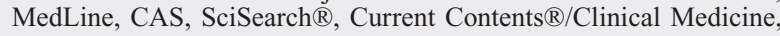

\section{Dovepress}

Journal Citation Reports/Science Edition, EMBase, Scopus and the Elsevier Bibliographic databases. The manuscript management system is completely online and includes a very quick and fair peer-review system, which is all easy to use. Visit http://www.dovepress.com/ testimonials.php to read real quotes from published authors.

Submit your manuscript here: http://www.dovepress.com/international-journal-of-nanomedicine-journal 